\title{
A HiSTÓRIA DE NÓS DOIS: REFLEXÓES ACERCA DA FORMAÇÃO E DISSOLUÇÃO DA CONJUGALIDADE
}

\author{
Kamêni Iung Rolim* \\ Maria Isabel Wendling**
}

\section{Resumo}

Atualmente as pessoas experienciam novas formas de construir vínculos conjugais e dissolvê-los, visto que estes se encontram cada vez mais fragilizados. Separaçôes e divórcios têm sido frequentes, ocorrendo várias vezes ao longo do ciclo vital, fato que não acontecia anteriormente. Esses processos podem ser vivenciados envoltos em níveis de saúde ou doença, e observa-se que tanto conflitos conjugais quanto a vivência do divórcio fomentam intensas demandas de procura por atendimento psicológico. O presente estudo propóe uma revisão teórica de estudos na área com vistas a problematizar tais fenômenos e ampliar a compreensão dos mesmos. São abordados os vínculos relacionais na formação e dissolução da conjugalidade, repercussōes e possibilidades de intervenção, partindo da perspectiva sistêmica acerca de aspectos relacionais envolvidos nesses processos. Observa-se que muitas mudanças sociais inerentes à pós-modernidade têm afetado a tônica da dinâmica conjugal, e suas especificidades carecem ser compreendidas para ampliar o potencial das intervençóes adotadas.

Palavras-chave: vínculos relacionais; conjugalidade; separação.

\section{Abstract}

THE STORY OF US: REFLECTIONS ON FORMATION AND DISSOLUTION OF MARRIAGE

Nowadays people experience new ways to build marriage bonds and dissolve them, since they are increasingly more vulnerable. Separations and

\footnotetext{
* Faculdades Integradas de Taquara (FACCAT), Taquara, RS, Brasil.
}

** Faculdades Integradas de Taquara (FACCAT), Taquara, RS, Brasil. 
divorces have been frequent, occurring several times throughout the life cycle, this fact used not to happen earlier. These processes can be experienced in different levels involving health and disease. It has been noticed that both marital conflict and divorce continue to boost intense demand for psychological care. The aim of this paper is to do a theoretical revision based on present studies in psychology with the objective to problematize such phenomena and amplify their comprehension. It is discussed the relational ties in the formation and dissolution of marital bonds, repercussions and possibilities of intervention, by using systemic perspective about the relational aspects involved in these processes. It is observed that many social changes intrinsic to Post-Modernity have been affected the marital dynamic and its specificities need to be understood to increase the potential of adopted interventions.

Keywords: relational links; marital; separation.

\section{Resumen}

LA HISTORIA DE NOSOTROS, LOS DOS. REFLEXIONES ACERCA DE LA FORMACIÓN Y DISOLUCIÓN DE LA PAREJA

Actualmente las personas viven la experiencia en nuevas formas de construir vínculos conyugales y deshacerlos, puesto que éstos se encuentran cada vez más frágiles. Separaciones y divorcios han sido frecuentes, ocurriendo varias veces a lo largo del ciclo vital, hecho que no ocurría anteriormente. Estos procesos pueden ser vivenciados, involucrados tanto a niveles de salud o de enfermedad, y, se observa que, tanto conflictos conyugales cuanto la vivencia del divorcio, alimentan intensas demandas de búsqueda por atendimiento psicológico. El presente estudio propone una revisión teórica de estudios en el área visando la problematización de tales fenómenos y la ampliación de la comprensión de los mismos. Son abordados los vínculos relacionales en la formación y disolución del matrimonio, repercusiones y posibilidades de intervención, partiendo de la perspectiva sistémica acerca de aspectos relacionales involucrados en estos procesos. Se observa que muchos cambios sociales inherentes a la Posmodernidad han afectado la tónica de la dinámica conyugal y sus especificidades carecen ser comprendidas para ampliar el potencial de las intervenciones adoptadas.

Palabras clave: vínculos relacionales; conyugal; separación. 


\section{Introduçáo}

A conjugalidade tem sido alvo de diversos estudos que culminaram na construção de uma literatura significativa, composta por diferentes enfoques para compreensão da dinâmica conjugal, em distintas abordagens e modelos terapêuticos (Féres-Carneiro \& Neto, 2010). Dentre essas abordagens teóricas, destaca-se a perspectiva sistêmica, que vislumbra "a formação e a dissolução da conjugalidade como um processo interacional” (Féres-Carneiro \& Neto, 2010, p. 269). Nesse sentido, o presente estudo busca apresentar algumas reflexóes acerca da formaçáo e dissolução da conjugalidade e suas repercussóes, considerando que são processos complexos e que envolvem diversos níveis do relacionamento.

Partindo disso, observamos que Anton (2002) traz que, de alguma forma, o ser humano está sempre conectado com outros e precisa deles para se estruturar e se desenvolver. Nesse aspecto, a conjugalidade pode ser vislumbrada como um processo de construção de uma realidade comum (Féres-Carneiro \& Neto, 2010), construída nas inter-relaçóes entre um casal e que se baseia no amor estabelecido por meio da confiança (Oltramari, 2009), podendo ser considerada, ainda, um relacionamento institucionalizado. Cabe salientar que a vivência da conjugalidade foi se alterando em consonância com o contexto histórico, sendo que na atualidade está marcada pela fragilidade dos laços afetivos (Bauman, 2004) em decorrência das crescentes relaçóes de consumo.

Nesse cenário, verifica-se que, de maneira geral, as relaçôes afetivas estão cada vez mais rápidas e cristalizadas (Bauman, 2004), sendo a dissolução dos vínculos relacionais do casal cada vez mais frequentes, pela separação ou por divórcio. Consoante Féres-Carneiro (2003), o divórcio é um doloroso processo e uma das principais demandas na clínica psicológica. Anton (2002) acrescenta que a separação e o divórcio são acompanhados de muitos conflitos e que, para serem compreendidos, devem ser vislumbrados à luz da história familiar, pois são fenômenos que apresentam aspectos transgeracionais. Aponta que tanto a escolha do cônjuge quanto a separação do mesmo pode estar imersa em níveis de saúde ou de patologia marcadas por modalidades de vínculos que transitam pelas fronteiras do sistema familiar.

Buscando promover uma revisão teórica sobre esses fenômenos, o presente artigo discutirá acerca dos vínculos relacionais na formação e dissolução da conjugalidade a partir do arcabouço teórico de autores que versam sobre os seguintes aspectos: vínculos relacionais, escolha do cônjuge, dissolução da conjugalidade e repercussóes e possibilidades de intervenção, considerando uma perspectiva sistêmica acerca de aspectos relacionais envolvidos nesses processos. 


\section{Vínculos: algumas consideraçóes}

A pessoa se forma através de suas relaçóes, tanto com outros seres humanos quanto com os objetos e símbolos que a cercam. Anton (2002) salienta a necessidade do outro para a estruturação da pessoa, já que a ausência de relações inviabilizaria o desenvolvimento e até mesmo a sobrevivência. Compreender as especificidades envolvidas no desenvolvimento dos vínculos é de suma importância para a compreensão de diferentes fenômenos psicossociais. Nesse aspecto, destacam-se os estudos desenvolvidos por Bowlby (1990), que suscitaram investigaçôes acerca da relação vincular com figuras primárias, desenvolvendo o autor, a partir destas observaçóes, a Teoria do Apego.

Os estudos desenvolvidos por Bowlby (1990) apontaram para o caráter adaptativo do vínculo na espécie humana, caracterizando-o como uma necessidade primária, tal qual a fome (Carvalho, Politano \& Franco, 2008). Assim, tem-se a compreensão de que o processo vinculativo está calcado sobremaneira nos laços afetivos precoces, que formam a base para a capacidade que o ser humano tem de criar novos e importantes laços. Isso é de extrema relevância para o desenvolvimento psicológico e é um processo contínuo, que inicia na infância e segue por todo o ciclo vital (Mota \& Matos, 2008). Embora a relevância dos vínculos na experiência humana seja unânime entre os estudiosos, existem divergências teóricas sobre como esses vínculos se desenvolvem e se processam (Brum \& Scherman, 2004). Algumas contribuições nesse sentido serão citadas a fim de ilustrar o escopo teórico construído ao longo do tempo sobre essa temática.

Brum e Scherman (2004) realizaram breve revisão teórica sobre o estudo da vinculação e apontaram que os estudos sobre o tema se iniciaram com Freud, que percebia a vinculação com a mãe (aqui vislumbrada como a primeira figura de referência, cuidadora) como proveniente de um instinto secundário a serviço da satisfação de uma necessidade básica, de comida e conforto. Spitz (1945) verificou que a ausência de vínculos ou a existência de vínculos inseguros promoviam prognósticos desenvolvimentais reservados. Por outro lado, Erikson (1980) enfatizou a importância dos vínculos para a construção da identidade, salientando que a mesma se constrói pela interação do indivíduo com seu meio. Já Winnicott (1963), focando nas relaçôes objetais, apontou a importância dos vínculos no desenvolvimento emocional primitivo e sua importância na luta dependência versus independência. Por fim, Brum e Scherman (2004) citam Bowlby, que considerou a importância do vínculo da díade mãe-bebê e cunhou o termo "apego" para caracterizar essa vinculação. 
Nesse veio, Cigoli (2002, p. 171) aponta a necessidade de considerar o vínculo como uma classe que compreende diversas áreas, citando "as relaçóes internalizadas, o pacto conjugal, as relaçóes familiares, as relaçóes de amizade e as relaçóes sociais". Cada uma dessas áreas possui autonomia, contudo o vínculo de cada área a uma classe implica "que ela influencie outras classes e seja influenciada por elas", constituindo uma rede de conexóes e nós. Por outro lado, Anton (2002) salienta o caráter transgeracional envolvido na construção dos vínculos, já que a qualidade destes também sofre influência daqueles que precederam a pessoa. Aponta também que a questão do vínculo é subjetiva, interna e a serviço de fatores inconscientes. Assim, a vinculação entre pessoas pode ser formada por laços fortes, estáveis e duradouros ou por laços frouxos, instáveis e frustrantes. Ambos os tipos de vínculos são motivados por questôes inconscientes, justificados por algo que concerne a ambas as pessoas que se vinculam como parceiros e respondem à atração inicial como uma escolha que os enlaça.

\section{Conjugalidade: formação e escolhas}

Para Berthoud e Bergami (1997, p. 49), que desenvolveram pesquisas com famílias paulistas, a primeira etapa do Ciclo Vital da Família é a fase da Aquisição, que inclui "a escolha do parceiro, a formação de um novo casal, a chegada do primeiro filho e a vida com os filhos pequenos”. Já Carter e McGoldrick (1995) pontuam, em pesquisas com famílias americanas, que a união de famílias no casamento, com a construção de um novo casal, se constitui como segunda etapa do Ciclo Vital da Família, que é precedida pela saída de casa dos jovens solteiros. Essas visóes sobre as etapas da formação da conjugalidade no Ciclo Vital Familiar não são excludentes: as autoras compartilham a constatação de que, devido às transformaçóes contínuas sofridas pela família e pela sociedade, torna-se cada vez mais difícil caracterizar a fase do ciclo vital em que se encontram indivíduos e famílias.

Carter e McGoldrick (1995) trazem que anteriormente a definição do relacionamento de um casal costumava ocorrer nas estruturas familiares tradicionais, vinculadas às anteriores. Atualmente, devido a diferentes transformaçóes na sociedade, as pessoas, por estarem menos amarradas por tradiçôes familiares, cada vez mais estão livres para vivenciarem relaçóes diferentes das experienciadas nas famílias de origem (Carter \& Mcgoldrick, 1995; Bauman, 2004). Liberdade caracterizaria a escolha do parceiro, por ser considerada a única escolha familiar que pode ser feita pela pessoa. Contudo, essa liberdade é relativa, pois está imer- 
sa em muitas expectativas sociais, pessoais e familiares e, em especial, motivada por aspectos inconscientes (Anton, 1998), sendo influenciada fortemente pelas relações com a família de origem (Lima, 2010). Cabe salientar a complexidade envolvida em tornar-se casal.

Zordan (2010, p. 27) aponta que a união conjugal sempre esteve presente na história da humanidade, contudo assume contornos e características diferentes de acordo com o contexto "político, social, religioso, cultural e econômico de cada momento histórico". Nesse aspecto, Puga (2007) aponta o casamento como uma construção sobremaneira social, cuja finalidade é garantir o controle social. Zordan (2010) salienta também que os casamentos na atualidade continuam influenciados pelo ideal de amor romântico surgido no século XVIII, coexistindo, no entanto, com os mais variados estilos de vida e de arranjos conjugais, incluindo relacionamentos heterossexuais, homossexuais, divórcio e recasamento, dentre outras possibilidades.

O casamento não é apenas a união de dois indivíduos; representa a modificação de, no mínimo, dois sistemas diferentes, as famílias de origem dos cônjuges, e o desenvolvimento de um terceiro subsistema, o casal (Carter \& Mcgoldrick, 1995). Berthoud e Bergami (1997, p. 56) apontam que a formação do casal é uma das possibilidades de desenvolvimento de vínculos duradouros e implica na construção gradual de vínculo propiciador de "apego, cumplicidade e também independência e autonomia emocional”. Por outro lado, o equilíbrio nessa relação é alcançado apenas quando ocorre a diferenciação emocional, tanto da família de origem quanto como indivíduos e casal. Berthoud e Bergami (1997, p. 56) citam os principais fatores que influenciam na construção dos vínculos de um casal: "a história de cada um, afinidades e diferenças culturais e os reais motivos da união".

Pincus e Dare (1981) identificam a conjugalidade como uma tentativa de encontro de felicidade e conforto, considerando que a família inicia com o casal e passa a influenciar na construção da personalidade das crianças que se desenvolvem nesse casamento, bem como no tipo de relação que terão no futuro. Já Anton (2002, p. 42) salienta que a vivência da conjugalidade inclui a criação de pactos e acordos conjugais que abarcam "crenças, valores e defesas próprios do casal, bem como de seus antecessores e contemporâneos mais significativos". Esse fenômeno está alicerçado na qualidade dos vínculos que iniciam na infância, constituindo-se numa longa aprendizagem que conduz a pessoa ao desenvolvimento da capacidade de amar e ser amada. Essas vivências dão, de certa forma, o tom dos vínculos que serão construídos na conjugalidade. Nesse aspecto, Lima (2010) aponta a necessidade de estudo dos aspectos que contribuem nos estabelecimentos de vín- 
culos nas relaçóes amorosas, chamando atenção para as relaçóes conjugais que resultam na violência contra a mulher.

Anton (2002) traz que as pessoas com quem se convive têm um importante papel, inclusive na vida adulta, e provocam reaçóes que contribuem para o desenvolvimento, para paralisação ou regressão. Nesse aspecto, a conjugalidade pode propiciar tanto elos sadios e construtivos quanto frustraçóes e sofrimentos. A escolha do cônjuge pode ser tanto por enamoramento ou paixáo quanto por fatores mais objetivos. Contudo, de uma forma ou outra, está sempre marcada pela subjetividade. Lima (2010) traz que a escolha do cônjuge sofre influências dos mecanismos de projeção e identificação, sendo que "podem sofrer influência direta do interjogo que se estabelece entre aquilo que o sujeito projeta no outro e aquilo que, desde os tempos mais primórdios, serviu-lhe de modelo identificatório" (Lima, 2010, p. 27).

No que tange à formação de vínculos na conjugalidade no contexto atual, Zordan (2010) salienta que continua associada ao amor, porém com significados distintos para ambos os sexos (Carter \& Mcgoldrick, 1995). Enquanto os homens vivenciam o casamento como a constituição da família, as mulheres o vivenciam como relação amorosa (Féres-Carneiro, 2001). O casamento representa uma relação muito intensa, que envolve intimidade e grande investimento afetivo (Féres-Carneiro, 2001), contudo tem perdido o status que ocupava anteriormente, que era de símbolo de transiçấo para o mundo adulto e para a paternidade (Carter \& Mcgoldrick, 1995). O lugar do casamento no ciclo vital tem sido dramaticamente alterado, tendo em vista a iniciação sexual cada vez mais precoce, o viver juntos com um ou entáo com vários parceiros antes de casar. Por sua vez, Zordan (2010, p. 27) pontua que o casamento já não é mais visto como única possibilidade ou obrigação, com a aceitação de que as pessoas "optem por estilos de vida que incluem ficar solteiro, viver com parceiros de qualquer um dos sexos, divorciar-se, casar-se novamente e não ter filhos”. Isto traz à tona uma questão que tem mobilizado cada vez mais estudos acerca de um problema que Andolfi (2002) caracteriza como dramático, tanto do ponto de vista social quanto familiar: a crescente fragilidade do sistema-casal.

\section{Fragilidade dos vínculos: o casal no contexto da contemporaneidade}

Consoante Walsh (2002), as enormes mudanças sociais repercutem na relação do casal, propiciando uma nova forma de viver a conjugalidade (Zordan, 
2010). Para Heilborn (2004), o panorama cultural dos anos 60 foi determinante para as mudanças de paradigmas vivenciadas no que tange à conjugalidade por ter sido um período de forte contestação à repressão e à autoridade. Tal período também foi marcado pelos valores de igualdade, liberdade, mudança e singularidade individuais (Heilborn, 2004), refletindo-se em expectativas frágeis de permanência nas relações e critérios de seleção inadequados (Gimeno, 1999).

No fenômeno da conjugalidade, estão presentes duas forças, desejo e amor (Bauman, 2004): o amor, como um impulso centrífugo, caracterizado pela vontade de cuidar e de preservar o objeto cuidado, e o desejo como uma força centrípeta, caracterizada pelo impulso de expandir-se, ir além. Essas forças permeiam várias esferas da sociedade atual, que é uma sociedade eminentemente de consumo, e também as relaçóes conjugais, que cada vez mais também se caracterizam por "relaçóes de bolso" (Catherine Jarvie, citada por Bauman, 2004, p. 36), pois "você as guarda no bolso de modo a poder lançar mão delas quando for preciso". São relaçôes instantâneas, das quais as pessoas têm controle e que são descartadas quando não atendem mais as expectativas.

Esse cenário propicia a fragilização dos vínculos humanos, aspecto que está inter-relacionado à crise do casal como instituição na atualidade. Nesse aspecto, Goldenberg (2010) traz reflexôes que denotam que na atualidade a fragilização dos vínculos chegou a um ponto em que os corpos tornaram-se um mero valor, um capital de consumo. Isso se caracteriza pelo fato de que pessoas que não possuem o corpo idealizado pela cultura vigente acabam por se tornarem "invisíveis", excluindo-se do que a autora chama de mercado matrimonial e mercado sexual.

Féres-Carneiro e Neto (2010) preconizam a necessidade de compreensão das problemáticas do casal, apontando as tensôes da individualidade e da conjugalidade como forças paradoxais presentes na vivência do casal no contexto contemporâneo. Satir (1995, p. 29) salienta que o casal é composto "por dois indivíduos e uma relação: eu, você, nós”. Essa é uma relação que demanda intenso investimento afetivo e temporal por parte dos cônjuges, contudo a presença de características individualistas no casamento, cada vez mais fortes, implica que esses aspectos sejam vivenciados pelo casal contemporâneo sob novas formas, (Cicco, Paiva, \& Gomes, 2005) que se refletem no aumento das expectativas e na idealização extremada que provocam tensôes e conflitos. Assim, Gomes e Paiva (2003) apontam que, a fim de se compreender a vivência da conjugalidade, há de se privilegiar uma visão distanciada do modelo institucional de casamento, considerando que o casamento na atualidade está ligado a noçóes de mutatividade, transformaçáo e flexibilidade em relaçáo ao novo e ao diferente. Trata-se de uma percepção paradoxal, com a constatação de inúmeras possibilidades de relaçóes 
conjugais, que incluem o casamento, separação, recasamento, unióes de pessoas do mesmo sexo, dentre outras configurações.

Partindo dessas reflexões, temos que Berger e Kellner (1970) descrevem o casamento como um ato dramático no qual dois estranhos, portadores de um passado individual diferente, se encontram e se redefinem. Isso traz à tona algumas tarefas da conjugalidade, que na pós-modernidade têm sido vivenciadas cada vez mais com mutatividade e rapidez.

Walsh (2002) chama atenção para o fato de que, não importando a cultura, os casais fazem uma espécie de contrato metafórico no início da relação, determinando não apenas se haverá ou não o casamento, mas especialmente estabelecendo as regras da própria relação. Nesse escopo, constroem papéis e regras de relação num processo circular e de influência recíproca. Esses papéis e regras são construídos a partir dos sistemas de crenças e das expectativas de cada um, estruturados a partir das experiências nas famílias de origem, bem como em outras experiências matrimoniais. Consoante Walsh (2002), esses constructos permeiam os modos de conceber e de ser marido e mulher, fazendo com que o casal construa uma realidade compartilhada, que é reforçada ou modificada a partir da experiência. Nesse sentido, Cigoli (2002) fala de idem do casal, ou seja, da imagem-semelhança entre os membros ratificada através de pactos expressos e pactos secretos. O pacto conjugal é uma área fundamental do vínculo que se coloca entre a declaração do compromisso (amar e respeitar na saúde e na doença...) e a presença de uma dimensão desconhecida, o pacto secreto, que diz respeito ao passado (relaçóes familiares, relaçóes internalizadas, relaçôes sociais) e ao presente-futuro.

Durante muito tempo, o pacto conjugal esteve subordinado à vontade das famílias de origem e às relaçôes de poder. Hoje, está imerso num pluralismo de modelos. Contudo, a harmonização entre pacto expresso e pacto secreto é uma tarefa que poucos casais conseguem fazer, e as dicotomias entre esses dois pactos se inserem na vivência da conjugalidade, bem como na sua dissolução, fenômeno cada vez mais frequente e que pode ser vivenciado imerso em níveis de saúde ou de doença.

\section{Dissoluçáo da conjugalidade: abordagem ecológico-sistêmica}

"A vida conjugal envolve tarefas, responsabilidades e compromissos que muitas vezes suscitam divergências, conflitos que os envolvidos não conseguem superar ou até mesmo não querem superar" (Zordan, 2010, p. 108). Se o casamento implica 
a construção de uma nova identidade para os cônjuges, o processo de separação, divórcio e redivórcio, por sua vez, implica a desconstrução dessa nova identidade, levando os cônjuges a uma redefinição (Féres-Carneiro, 2003). O processo de dissolução da conjugalidade, fato cada vez mais comum na atualidade, tem sido uma das principais demandas de procura de terapia no contexto clínico. Zordan (2010) salienta que, mesmo a dissolução da conjugalidade sendo um fato cada vez mais comum, isso não a isenta do fato de ser uma interrupção no ciclo de vida familiar, levando a profundas transformaçóes associadas a mudanças, perdas e ganhos, tanto para os cônjuges quanto para o grupo familiar como um todo. Considerando a complexidade envolvida nesse fenômeno, Zordan (2010) aponta que o processo de dissolução da conjugalidade pode ser compreendido pelo modelo ecológico-sistêmico (Bronfenbrenner \& Morris, 1998), propondo o esquema representado pela Figura 1:

Figura 1: A separação conjugal sob a abordagem ecológico-sistêmica

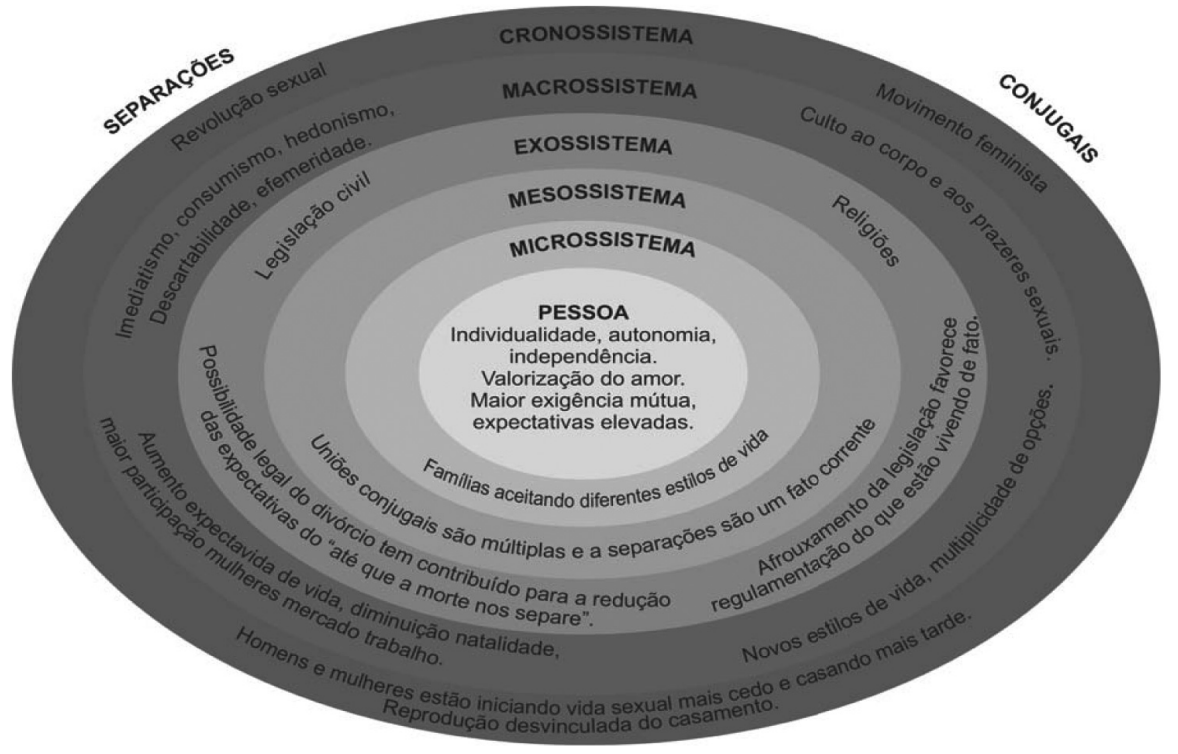

Fonte: Zordan (2010)

Sob essa perspectiva, o processo de dissolução da conjugalidade é vislumbrado à luz das inter-relaçóes entre a pessoa e diversos sistemas: microssistema, representado pela família aceitando diferentes estilos de vida; o mexossistema, que diz respeito à interconexão entre um ou mais sistemas e representa as múltiplas possibilidades de relaçóes conjugais e as separaçóes como um fato corrente; o exossistema, representando as mudanças religiosas e na legislação no que tange 
às separações e divórcios, que têm cada vez mais aceitação e regulamentação; o macrossistema, incluindo as características de consumismo e imediatismo da sociedade atual; e o cronossistema, que traz as mudanças ocorridas na sociedade ao longo do tempo, tais como a revolução sexual, o início mais cedo da vida sexual tanto para homens quanto para mulheres e o movimento feminista. Esse modelo permite vislumbrar a complexidade envolvida no processo de dissoluçáo da conjugalidade, propondo uma leitura sistêmica desses processos.

Dessa forma, temos que a pessoa está imersa e influenciada pelas inter-relações com esses contextos mais amplos. No que tange à pessoa, Zordan (2010) aponta que as expectativas frágeis de permanência no casamento, a hipervalorização do individualismo, a busca de realização pessoal e a independência econômica das mulheres constituem-se como as principais balizadoras da dissoluçáo da conjugalidade, sendo que ainda são as mulheres que buscam maior definição em suas relaçóes, demonstrando maior preocupação a respeito das relaçóes conjugais. O desejo de separação é apontado por Féres-Carneiro e Neto (2010) como um desejo eminentemente feminino.

Já no que tange às causas psicossociais, é verificado que permeiam conflitos que levam à ruptura do laço conjugal, destacando-se a influência da família de origem e do meio social sobre as pessoas que vivenciam o processo de separação (Zordan, 2010). Ademais, a infidelidade conjugal e a traição masculina são apontadas como principal causa das separaçóes. Lopes (2006) aponta a idade dos cônjuges, o número de filhos e a idade dos mesmos como fatores preditores de separação conjugal. Zordan (2010) chama atenção para o fato de que a maioria dos estudos realizados sobre essa temática no Brasil tenha se centrado em famílias com filhos pequenos e adolescentes, ao passo que a separação pode ocorrer em qualquer fase do ciclo vital.

Toda a vivência da separação implica em muito sofrimento. Caruso (1989) afirma que a separação significa, em alguma medida, a presença da morte na vida, uma vez que os cônjuges vivenciam uma sensação de morte recíproca. Conforme afirma Féres-Carneiro (2003), apesar de em alguns casos a separação representar melhor qualidade de vida, ainda assim trata-se de um processo muito doloroso e que inclui a vivência de muito sofrimento.

\section{Separação e divórcio: repercussóes e possibilidades}

Propondo reflexóes acerca de especificidades da dissolução de vínculos conjugais, Willi (1995) pontua que é um erro crasso pensar que o divórcio acaba 
com a vida comum entre os cônjuges. Ao contrário, muitas vezes o divórcio significa justamente a continuidade do casamento, sob outra roupagem. Aponta casos em que, mesmo um dos cônjuges recasando, sobrevive a velha relaçáo diádica entre o casal separado. Em suma, a separação pode ser vivenciada como uma situação dolorosa e ofensiva na qual pode ocorrer que, mesmo separados, os cônjuges continuem apegados um ao outro.

Já Féres-Carneiro e Neto (2010) apontam que a dissolução da conjugalidade deve ser compreendida como um processo no qual os padróes de manutenção da relação são modificados, fazendo com que não seja mais definida pelos cônjuges, ou pelo menos por um deles, como uma relação conjugal. Esse é um processo abrupto e descontínuo, envolvendo um longo e doloroso processo que pode durar muitos anos (Féres-Carneiro, 2003). Por outro lado, Zordan (2010) aponta que, se anteriormente a dissoluçáo da conjugalidade envolvia os cônjuges em preocupaçóes com as repercussóes para os filhos e grupos familiares, hoje em dia percebe-se que a conduta pautada na autonomia e individualidade preconiza a satisfação pessoal. Assim, cada vez mais a separação ocorre como solução para os conflitos oriundos da conjugalidade.

Féres-Carneiro (2003) pontua que o grande número de divórcios tem ocorrido devido a os cônjuges hipervalorizarem o casamento a ponto de não aceitarem permanecer em uma relação que não corresponda a suas expectativas: o divórcio refletiria uma exacerbada exigência dos cônjuges. Isso pode explicar por que, na maioria dos casos, os divorciados acabam caminhando para o recasamento. Zordan (2010) observa que os homens tendem, após uma separação, a procurar novas relaçóes com mais facilidade e atribui isso ao papel social que é imposto a eles desde a infância (exercer atividades remuneradas fora do lar e necessitar de ajuda para gerenciar a própria vida). Já as mulheres teriam mais dificuldade em iniciar novas relaçóes após uma separação devido ao peso da desilusão sofrida.

No que tange às reverberaçóes para o indivíduo, Zordan (2010) e Féres-Carneiro (2003) sugerem que o fato de a maioria das separaçóes ser solicitada por mulheres explique o porquê de estas apresentarem-se mais aptas a seguirem em frente após uma separação. Já para os homens, que tendem a perceber o casamento associado à constituição de família, a vivência da separação costuma ser um processo imerso em maiores níveis de sofrimento, pois a separação, nesses casos, representa não apenas a dissolução da conjugalidade, mas também da família.

Ademais, observa-se que a dissolução de vínculos conjugais impele os cônjuges à tarefa de reconstrução de nova identidade, com repercussóes diversas. A separaçáo de um casal reverberará nos sistemas e contextos em que estava inserido, direta ou indiretamente: o vínculo com os amigos em comum costuma ficar 
desestabilizado; o contato com as famílias de origem se intensifica (Willi, 1995). Quanto às repercussões, destaca-se que, no que tange aos casais com filhos, percebe-se que muitas vezes há a dificuldade de separar conjugalidade de parentalidade, como se a separação fosse dos filhos e não do casal, o que gera profunda crise, a qual atinge todo o sistema familiar (Féres-Carneiro, 2003).

Contudo, Willi (1995) salienta que a dissolução da conjugalidade pode representar possibilidades de crescimento e evolução. Partindo da premissa de que uma relação conjugal satisfaz certas necessidades e que a patologia nasce quando as necessidades não são satisfeitas reciprocamente ou são imaturas, às vezes a separação é salutar. Contudo, Willi (1995) problematiza que a área da psicologia tem estudado exaustivamente a patologia relacionada ao casamento, com aspectos tais como rivalidade, luta pelo poder, perda de autonomia, fusionalidade e simbiose. Entretanto considera que ainda há pouco conhecimento sobre o que um casamento funcional pode realizar de positivo e de fato realiza; "as pessoas casadas vivem melhor do que as não casadas" (Willi, 1995, p. 39).

Ao considerar que a separação tem sido uma das demandas mais frequentes nas clínicas psicológicas, Féres-Carneiro (2003) explicita que muitas vezes os casais chegam com a demanda de "se separarem bem" e, ao longo do processo terapêutico, acabam entrando em contato com o desejo inconsciente de náo-rompimento da relação. Por outro lado, há casais que procuram atendimento para manterem-se casados e acabam se separando.

\section{Consideraçóes finais}

A presente revisão teórica buscou apresentar um apanhado acerca dos principais aspectos relacionados à compreensão da conjugalidade e sua dissolução, preconizando o papel dos vínculos nesses fenômenos a partir de uma abordagem sistêmica. Apresenta apenas uma visão geral do grande escopo teórico construído sobre a temática, considerando a importância desses aspectos para atuação do psicólogo no que tange à compreensão e intervenção junto aos casais em crise. Salienta-se ainda a importância de que esses aspectos sejam levados em conta náo apenas na atuação com casais no contexto clínico, pois são demandas que perpassam outros contextos de atuação do psicólogo. Cabe salientar que os conflitos emanados da conjugalidade e sua dissolução podem fomentar sintomatologias diversas e ser fonte de intenso sofrimento para os envolvidos no contexto, cabendo ao psicólogo estar atento e aguardar o momento terapêutico de abordar aspectos conjugais em suas intervenções, sejam individuais, com casais ou com famílias. 
Destaca-se ainda a importância de investigaçóes sobre essa temática na atualidade, tendo em vista as intensas mudanças sociais impingidas pela pós-modernidade, que tem fomentado o imediatismo e o consumismo até mesmo nas relaçóes pessoais. Sugere-se o desenvolvimento de estudos que abordem esse aspecto, vislumbrando as influências macrossistêmicas na vivência da conjugalidade nesse contexto, o que pode propiciar a construção e a qualificação de intervenções em maior consonância com as novas formas de experienciar a conjugalidade.

Considera-se que tais reflexóes podem auxiliar estudantes e pesquisadores a continuarem desenvolvendo pesquisas nessa área em função das constantes mudanças que nossa sociedade vem sofrendo nos últimos anos e que afetam de alguma maneira as relações, assim como as configurações familiares decorrentes.

\section{Referências}

Andolfi, M. (2002). A terapia do casal como processo transformativo. In M. Andolfi. A crise do casal: uma perspectiva sistêmico-relacional (pp. 99-122). Porto Alegre: Artmed Editora.

Anton, I. C. (1998). A escolha do cônjuge: um entendimento sistêmico e psicodinâmico. Porto Alegre: Artmed.

Anton, I. C. (2002). Homem e mulher: seus vinculos secretos. Porto Alegre: Artmed Editora.

Bauman, Z. (2004). Amor líquido: sobre a fragilidade dos laços humanos. Rio de Janeiro: Jorge Zahar.

Berger, P., \& Kellner, H. (1970). Marriage and the construction of reality. In P. H. Dreiazel (Ed.). Recent sociology (pp. 220-229). New York: The Mac Millow Company.

Bowlby, J. (1990). Apego e perda: apego, a natureza do vinculo. [2a ed.] São Paulo: Martins Fontes. (Original publicado em 1969)

Berthoud, C. M. E., \& Bergami, N. B. B. (1997). Família em fase de aquisição. In C. M. O. Cerveny, \& C. M. E. Berthoud (Eds.). Família e ciclo vital: nossa realidade em pesquisa (pp. 47-75).

Bronfenbrenner, U., \& Morris, P. A. (1998). The ecology of developmental processes. In W. Damon, \& R. M. Lerner (Eds.). Handbook of child psychology, v. 1: Theoretical models of human development (pp. 993-1028). New York: John Wiley.

Brum, E. H. M., \& Scherman, L. (2004). Vínculos iniciais e desenvolvimento infantil: abordagem teórica em situação de nascimento de risco. Ciência e Saúde Coletiva, 9(2), 457-467.

Carter, B., \& Mcgoldrick, M. (1995). As mudanças no ciclo de vida familiar: uma estrutura para a terapia familiar [2ed.]. Porto Alegre: Artmed. 
Carvalho, A. M. A., Politano, I., \& Franco, A. L. E. S. (2008). Vínculo interpessoal: uma reflexão sobre diversidade e universalidade do conceito na teorização da psicologia. Estudos de Psicologia, 25(2), 233-240.

Caruso, I. (1989). A separação dos amantes: uma fenomenologia da morte. São Paulo: Editora Cortez.

Cicco, M. F., Paiva, M. L., \& Gomes, I. C. (2005). Família e conjugalidade: o sintoma dos filhos frente à imaturidade do casal parental. Psicologia Clinica, 17(2), 53-63.

Cigoli, V. (2002). O rompimento do pacto: tipologia do divórcio e rituais de passagem. In M. Andolfi (Ed.). A crise do casal: uma perspectiva sistêmico-relacional (pp. 171-200). Porto Alegre: Artmed.

Erikson, E. (1980). O ciclo vital completo. Porto Alegre: Artmed.

Féres-Carneiro, T. (2001). Casamento contemporâneo: construção da identidade conjugal. In T. Féres-Carneiro (Ed.). Casamento e família: do social à clínica (pp. 67-80). Rio de Janeiro: Nau.

Féres-Carneiro, T. (2003). Separação: o doloroso processo de dissolução da conjugalidade. Estudos de Psicologia, 8(3), 367-374.

Féres-Carneiro, T., \& Neto, O. D. (2010). Construção e dissolução da conjugalidade: padróes relacionais. Paidéia, 20(46), 269-278.

Gomes, I. C., \& Paiva, M. L. S. C. (2003). Casamento e família no século XXI: possibilidade de holding? Psicologia em Estudo, 8 (número especial), 3-9.

Gimeno, A. (1999). La familia: el desafio de la diversidad. Barcelona: Ariel.

Goldenberg, M. (2010). O corpo como capital: gênero, casamento e envelhecimento na cultura brasileira. Redige, 1(1), 191-200.

Heilborn, M. L. (2004). Dois é par: gênero e identidade sexual em contexto igualitário. Rio de Janeiro: Garamond.

Lima, G. Q. (2010). História de vida e escolha conjugal em mulheres que sofrem de violência doméstica. (Dissertação de Mestrado. Curso de Pós-Graduação em Psicologia Clínica, Pontifícia Universidade Católica do Rio Grande do Sul, Porto Alegre, RS).

Lopes, N. A. (2006). Casamento, dissolução conjugal e suas funçōes adaptativas. (Dissertação de Mestrado, Universidade Federal do Rio Grande do Norte, Natal, RN).

Mota, C. P., \& Matos, P. M. (2008). Apego, conflito e auto-estima em adolescentes de famílias intactas e divorciadas. Psicologia: reflexão e crítica, 22, 344-352.

Oltramari, L. C. (2009). Amor e conjugalidade na contemporaneidade: uma revisão de literatura. Psicologia em Estudo, 14 (4), 669-677.

Pincus, L., \& Dare, C. (1981). Psicodinâmica da família. Porto Alegre: Artes Médicas.

Puga, V. L. (2007). Casar e separar: dilema social histórico. Esboços, 17, 157-172.

Satir, V. (1995). A mudança no casal. In M. Andolfi; C. Angelo, \& C. Saccu (Orgs.). O casal em crise. São Paulo: Summus Editorial. 
Spitz, R. A. (1945). Hospitalism: an inquiry into the genesis of psychiatric conditions in early childhood. Psychoanalytic Study of the Child, 1, 53-74.

Zordan, E. P. (2010). A separação conjugal na contemporaneidade: motivos circunstâncias e contextos. (Tese de Doutorado. Curso de Pós-Graduação em Psicologia, Pontifícia Universidade Católica do Rio Grande do Sul, Porto Alegre, RS).

Walsh, F. (2002). Casais saudáveis e casais disfuncionais? Qual a diferença? In M. Andolfi (Ed.). A crise do casal: uma perspectiva sistêmico-relacional (pp. 13-28). Porto Alegre: Artmed.

Winnicott, D. (1963). Da dependência à independência no desenvolvimento do indivíduo. In D. Winnicott. O ambiente e os processos de maturaçâo (pp. 79-87). Porto Alegre: Artes Médicas.

Willi, J. (1995). A construção diádica da realidade. In M. Andolfi (Ed.). O casal em crise (pp. 38-47). São Paulo: Sumus.

Recebido em 3 de novembro de 2011 Aceito para publicação em 24 de agosto de 2012 